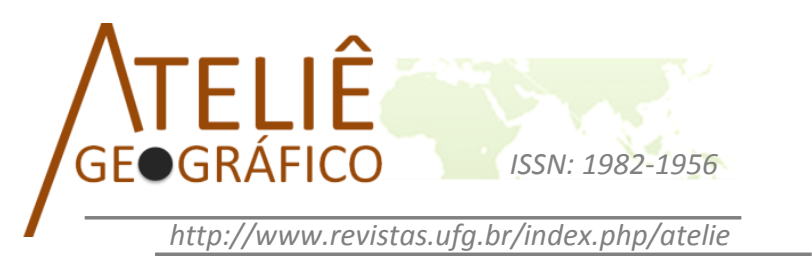

\title{
Da Geopolítica dos Estados a Geopolítica das Corporações Transnacionais: a metamorfose do Cerrado brasileiro em soja e cana-de- açúcar ${ }^{1}$
}

\author{
From Geopolitics of States to Geopolitic of Transnational \\ Corporation: the metamorphosis of brazilian Cerrado in \\ soybean and sugarcane
}

De la Geopolítica de los Estados a Geopolítica de las Empresas Transnacionales: la metamorfsis del Cerrado de Brasil en soya y caña de azúcar

\author{
Elisa Pinheiro de Freitas \\ Universidade de São Paulo \\ elisafreitas@usp.br
}

\begin{abstract}
Resumo
Discutir a Geopolítica e discernir qual é o vínculo que esse saber tem com o Estado e, atualmente, com as Corporações, sem dúvida, não é uma tarefa nada trivial. Nesse sentido, o desafio que este artigo se propõe é o de buscar demonstrar que as disputas por território, recursos, poder entre outras que no passado envolveram e foram lideradas basicamente pelos Estados nacionais, no período atual essa competição tem sido conduzida muito mais pelas Corporações Transnacionais. Não obstante, como se altercará, os Estados nacionais e suas ações ainda são imprescindíveis para que as estratégias corporativas alcancem a máxima eficácia, uma vez que o capitalismo enquanto sistema econômico hegemônico apenas se realiza quando se amalgama com o Estado. E no caso do Brasil, as Corporações Transnacionais que atuam nos circuitos espaciais produtivos da soja e da cana-de-açúcar tem imprimido novas dinâmicas no Cerrado que progressivamente se metamorfoseia em soja e cana, cultivos estes
\end{abstract}

\footnotetext{
${ }^{1}$ Este artigo é resultante de uma pesquisa doutoral financiada pela Fundação de Amparo à Pesquisa do Estado de São Paulo (FAPESP) processo n. 2010/02452-8 junto ao Programa de Pós-Graduação em Geografia Humana do Departamento de Geografia da Universidade de São Paulo (USP).
} 
que visam prioritariamente a produção de commodities para abastecimento do mercado global.

Palavras-chave: Geopolítica dos Estados, Geopolítica das Corporações Transnacionais, Circuitos espaciais produtivos.

\begin{abstract}
Discuss the Geopolitical and discern what is the bond that one has to know the State and currently with the Corporations certainly is not a trivial task. In this sense, the challenge that this paper proposes is to seek to demonstrate that disputes over territory, resources, power and others involved in the past and were led primarily by national states, in the current period, this competition has been driven more by Transnational Corporations. Nevertheless, as is wrangle, national states and their actions are still needed so that the corporate strategies achieve maximum effectiveness, since capitalism as the hegemonic economic system will be realized when it amalgamated with the State. And in the case of Brazil, Transnational Corporations that operate in productive spatial circuit of soybean and sugar cane have printed new dynamics in the Cerrado that gradually metamorphoses into soybean and sugarcane crops they aimed primarily commodity production to supply the global market.
\end{abstract}

Keywords: Geopolitics of the States, Geopolitics of Transnational Corporations, Productive spatial circuit.

\begin{abstract}
Resumen
Discutir la Geopolítica y discernir lo que es el vínculo que este conocimiento tiene con el Estado y, en la actualidad, con las Corporaciones, sin duda no es una tarea trivial. En este sentido, el desafío que este trabajo propone es tratar de demostrar que las disputas por el territorio, los recursos, la energía y otras personas involucradas en el pasado y fueron conducidos principalmente por los Estados nacionales, en el período actual, esta competencia ha sido impulsado más por empresas Transnacionales. Sin embargo, al igual que disputa, los Estados nacionales y sus acciones que aún se necesitan para que las estrategias de las empresas a alcanzar la máxima eficacia, ya que el capitalismo como sistema económico hegemónico se realizará cuando se fusionó con el Estado. Y en el caso de Brasil, las empresas transnacionales que operan en la producción de circuitos espaciales de la soja y la caña de azúcar ha impreso una nueva dinámica en el Cerrado que metamorfosea poco a poco en la soja y la caña de azúcar que se dirigen principalmente a la producción de mercancías para abastecer el mercado mundial.
\end{abstract}

Palabras-clave: Geopolítica de los Estados, Geopolítica de las Empresas Transnacionales, Circuitos espacio productivo.

\title{
Introdução
}

Anterior a sua sistematização enquanto saber científico-acadêmico que se deu no século XIX, a Geografia e tudo aquilo que dizia respeito ao conhecimento dos lugares, das regiões, dos territórios, dos espaços já figuravam como saberes estratégicos os quais constituíam o métier da arte de governar: 
Geography, in addition to its vast importance to social life and the art of government... acquaints us with the occupants of the land and ocean and the vegetation, fruits, and peculiarities of the various quarters of the earth, a knowledge of which marks him who cultivates it as a man earnest in the great problem of life and happiness (ESTRABÃO, 1892 apud HARTSHORNE, 1939, p. 36).

Fundador da Ciência Política, Maquiavel (2007) buscou demonstrar que as ações políticas dos governantes estavam sujeitas as vicissitudes das condições histórico-geográficas. Assim, entendia que para uma ação política fosse eficaz era preciso que virtù e fortuna se entrelaçassem. Lembrando que por virtù entende-se como sendo a capacidade humana de enfrentar, por meio da ação política, as condições de existência, sejam elas adversas ou não. A fortuna refere-se ao curso da existência ou do destino que pode, eventualmente, ser ou não favorável à sociedade em geral. Para o autor de $O$ príncipe (1513), o êxito de um Estado, portanto, era resultante da confluência entre uma ação política eficaz e uma situação histórico-geográfica singular.

Conforme explicitou Hartshorne (1939, p. 37), o progresso da Geografia entre os séculos XVII e XVIII esteve atrelado ao utilitarismo. O conhecimento sobre os lugares servia de suporte para os governos ou para a ação política. O saber geográfico era um meio para se atingir os fins. Assim, a Geografia por muito tempo constituiu-se como sendo apenas um instrumento para a história e para o governo, na medida em que tinha de produzir conhecimentos e informações sobre as áreas ou unidades políticas. A ação política pressupunha amplo conhecimento do terreno. Assim, os primeiros passos da Geografia se dirigiram para sua afirmação como instrumento para a ação política. A gênese da Geografia é Política. Não é sem razão que Yves Lacoste (1998) afirmara no título do seu manifesto que a Geografia "serve, em primeiro lugar para fazer a guerra". A Geopolítica, dessa forma, não é uma caricatura e nem uma pseudogeografia. A Geopolítica é na realidade o âmago da Geografia, a sua verdade mais profunda e recôndita.

Alexander Von Humboldt, autor de $O$ cosmos (1845) e um dos fundadores, juntamente com Karl Ritter, da Geografia Clássica, foi treinado como geógrafo para atuar a serviço do governo alemão (HARTSHORNE, 1939). Contudo, a sua aproximação com George Forster levou-o a mudar o seu interesse em direção a Geografia científica e de âmbito acadêmico.

Muitos acontecimentos marcaram o século XIX. A expansão do capitalismo industrial para além da Inglaterra, abarcando também as nações da Europa Ocidental, notadamente a Alemanha e a França, engendrou uma ordem 
geopolítica que ficou conhecida como Concerto da Europa (1822-1875). Convém destacar que o conceito de ordem geopolítica diz respeito a um conjunto de idéias, concepções, normas, instituições que são forjadas pelos grupos de maior poder político e por meio das quais a economia política internacional opera em diferentes períodos históricos. Lembrando que o adjetivo 'geopolitica' designa que toda ordem internacional condiciona-se aos elementos de caráter geográfico (AGNEW E CORBRIDGE, 1995).

Sob a ordem geopolítica do Concerto da Europa, as potências Europeias estabeleceram no Congresso de Berlim (1885) o esquartejamento da África e da Ásia em busca de matérias-primas para as suas indústrias e de mercado para os seus produtos. E foi dentro desse contexto, que emergiu a Geografia enquanto disciplina científica, pois a descrição dos territórios coloniais para se descobrir o que eles continham em termos de recursos naturais consistiu em uma das tarefas fundamentais para subsidiar os Estados nacionais (GOTTMANN, 1973).

Mas, para além das descrições dos territórios, era preciso explicar as diferenças entre os lugares em termos de povoamento, de organização dos espaços, entre outros fatos. A constituição do Estado territorial moderno era tida pelos filósofos políticos como um dos fenômenos que precisava ser compreendido. Faltava à teoria da filosofia política sobre a origem do Estado às considerações sobre suas bases materiais, embora Maquiavel, Hobbes, Turgot e Montesquieu já tivessem aduzido sobre a interferência das condições geográficas na conformação dos Estados e das sociedades. Não obstante, foi o geógrafo alemão Friedrich Ratzel, fundador da Geografia humana que ponderou acerca das teorizações formuladas para explicar a genealogia do Estado (CAPEL, 1983).

Segundo Ratzel, a filosofia política negligenciou ou não aprofundou devidamente as reflexões de como os fatores geográficos tendem a influenciar as sociedades. Em sua Antropogeografia (1882), Ratzel retomou as idéias dos autores da antiguidade (Hipócrates e Estrabão) que haviam demonstrado como os elementos geográficos condicionavam o desenvolvimento das organizações sociopolíticas e da história. Ratzel também era conhecedor das concepções que nortearam os filósofos e cientistas políticos modernos. E criticou a teoria do Estado de Natureza porque os formuladores não incluíram o fator geográfico para explicar como se deu a passagem da humanidade do estágio de natureza (período pré-técnico) para o estágio sociopolítico (civilização):

da mesma forma, aqueles que interessaram pelo modo como o homem passou do estado de natureza ao estado social negligenciaram o elemento geográfico, representado pela união dos indivíduos singulares, com o objetivo de adquirirem maior 
força e segurança, e pela conseqüente fusão das suas porções de território (RATZEL, 1990, p. 35, grifo nosso).

$\mathrm{Na}$ concepção ratzeliana, a gênese do Estado nacional estava vinculada à defesa e à segurança do espaço vital ou do território. Outro fato relevante a ser considerado em relação às idéias de Ratzel é que ele demonstrou que a ciência política e a sociologia não deram a devida importância para o papel do território no desenvolvimento da sociedade. Para Ratzel constituía-se num grave erro metodológico desconsiderar o papel da íntima relação do ser humano com o solo (MORAES E COSTA, 1996; CASTRO, 2005; BECKER, 2006).

Mas, o que Ratzel compreendia por estreita relação do ser humano com o território? Para o autor, esse vínculo revelava-se através do aproveitamento e do incremento do/no território, ou seja, na medida em que a humanidade conhecia profundamente as leis da natureza, ela conseguia se libertar do jugo imperioso, e transformava o território em fonte de recursos (alimento, habitação, vestuário etc.).

Além disso, Ratzel demonstrou que na medida em que a população cresce em número, se expande o território. $\mathrm{Na}$ visão dele, historicamente, os povos que revigoravam suas forças foram aqueles que se expandiram territorialmente. Nesse aspecto, nota-se uma apologia e justificativa ao colonialismo como mecanismo de incremento territorial. Na visão de Ratzel o que vinculava o povo ao seu território eram os recursos naturais, pois, por exemplo:

\footnotetext{
a civilização conjunta da Grã-Bretanha, da Alemanha, da Bélgica está hoje (1899) em relação mais estreita com os recursos em carbono e ferro daqueles países do que há cem anos; e esta relação constituiu exatamente um novo elo, antes não existente ou não percebido, que liga o povo ao seu território (RATZEL, 1990, p. 71, grifo nosso).
}

Para Ratzel o território constituía-se em fonte de recursos. E quanto mais a sociedade estreita laços com a sua base territorial, mais se torna necessário a constituição de um Estado como ator político capaz de oferecer proteção aquela dada sociedade contra outros Estados (inimigos e ou aliados). Assim, é possível afirmar que para Ratzel, o território consistia em um poderoso motor para o desenvolvimento do Estado moderno.

A Antropogeografia de Ratzel está profundamente vinculada a sua Geografia Política. Para Ratzel, as condições físicas do meio interferiam na organização dos territórios e na conformação dos Estados. Ainda, tendo por base as teorias desenvolvidas por Darwin e por Spenser no campo da biologia e 
da sociologia respectivamente, Ratzel comparou o Estado a um organismo, ou melhor, a "um corpo vivo que se estendeu sobre uma parte da terra e se diferenciou de outros corpos que igualmente se expandiram por fronteiras ou espaços vazios" (RATZEL, 1990).

Dessa forma, Ratzel se consolidou como o teórico do determinismo geográfico e as suas concepções influenciaram as Escolas francesas e angloamericanas de Geografia. Contudo, derivariam de sua Geografia Política as doutrinas Geopolíticas do geógrafo inglês Halford John Mackinder, do cientista político sueco Rudolf Kjellén e do general e geógrafo alemão Karl Haushofer (LACOSTE, 1998). Convém destacar que a Geopolítica se diferencia da Geografia Política na medida em que aquela está na base da "formulação das teorias e projetos de ação voltados às relações de poder entre os estados e as estratégias de caráter geral para os territórios nacionais e estrangeiros, de modo que estaria mais próxima das ciências políticas aplicadas, sendo assim mais interdisciplinar e utilitarista que a primeira" (COSTA, 2008).

Dentre as teorizações formuladas por Ratzel em sua Geografia Política, o conceito de espaço vital direcionou as doutrinas de geopolítica. Com o advento da ordem geopolítica Inter-imperialista (1875-1945), as potências da Europa Ocidental passaram a disputar territórios coloniais com vistas a ampliar seus respectivos espaços vitais já que um Estado seria mais forte quando incrementasse o seu território através da utilização dos recursos naturais. Entre as principais conseqüências da ordem geopolítica Inter-imperial destaca-se as duas Grandes Guerras Mundiais, sendo que o caráter utilitário que marcou o desenvolvimento da geopolítica bem como o envolvimento da escola geopolítica alemã com o nazismo concorreu para a estigmatização daquele corpus teórico (GEORGE, 1980; CAPEL, 1983; CASTRO, 2005). Não obstante e, por mais paradoxal que possa parecer, as principais teorizações sobre espaço e poder foram formuladas pela Geografia Política e pelo seu braço utilitário, a Geopolítica, em decorrência do vínculo daquelas com o Estado (SOJA, 1993).

Após a Segunda Guerra Mundial, emergiu uma nova ordem geopolítica que ficou marcada pela Guerra Fria. Que mudanças se verificaram após o grande conflito mundial? E qual seria o papel da Geopolítica dentro dessa nova ordem?

\section{Hegemonias em mudanças: a ascensão dos EUA como superpotência global}

Se a ordem geopolítica do Concerto da Europa fora conduzida pela Inglaterra como sendo o primeiro Estado nacional a se tornar de fato 
internacional, a ordem geopolítica da Guerra Fria (1945-1990) será modelada pela hegemonia dos EUA. Destaca-se que o termo hegemonia foi discutido tanto por Agnew e Corbridge (1995) quanto por Arrighi (1996) tendo por base as formulações teóricas de Gramsci (1975) que, por sua vez, teve em Maquiavel a principal fonte de inspiração.

Para Arrighi (1996, p. 27-28) a hegemonia mundial "refere-se especificamente à capacidade de um Estado exercer funções de liderança e governo sobre um sistema de nações soberanas. (...) [O conceito de hegemonia] é uma reformulação da concepção de Maquiavel sobre o poder como uma combinação de consentimento e coerção". Agnew e Corbridge (1995) compreendem, assim como Arrighi, que a hegemonia constitui-se num entrelaçamento das relações de poder tanto consensuais quanto coercitivas.

Combinando o soft power com o hard Power (NYE, 1990), os EUA assumiram a liderança do sistema internacional constituído pós-1945. Isto significou, também, a ascensão de instituições supra-estatais tais como a Organização das Nações Unidas (ONU) bem como o advento do capitalismo de Corporações. Idealismo [paz baseada na ONU] e realismo [difusão do capitalismo corporativo], ambos, foram e ainda são articulados neste período de hegemonia americana (COSTA, 2008). Ademais, o Tratado de Bretton Woods (1945), engendrou as bases para o controle das finanças mundiais pelos EUA, controle esse que se efetuaria através do Fundo Monetário Internacional (FMI), do Banco Mundial (BIRD) e do Acordo Geral sobre Tarifas e Comércio (GATT), hoje Organização Mundial do Comércio (OMC). (GOTTMANN, 1973; LIPIETZ, 1988; ARRIGHI, 1996; MORGENTHAU, 2003).

Três aspectos adotados pela Geopolítica norte-americana influíram diretamente na constituição da ordem geopolítica da Guerra Fria sob a égide dos EUA: a) a concentração econômica, isto é, a consolidação de um modelo de capitalismo baseado nas grandes Corporações Transnacionais (TNC's); b) a difusão desse padrão de capitalismo e c) a defesa intransigente da livre iniciativa.

As Corporações Transnacionais de origem norte-americana, com o apoio do próprio governo norte-americano, imiscuíram-se nas políticas internas dos Estados nacionais da América Central e da América do Sul. O caso do imperialismo exercido pela United Fruit, na Guatemala, e pela Standard Oil praticamente em todos os lugares do mundo foi amplamente divulgado e conhecido (COUTINHO E SILVEIRA, 1957; GEORGE, 1967).

O governo de Arbenz, na Guatemala constituiu-se num exemplo concreto de como era difícil enfrentar os interesses das Corporações Americanas. Em 1947, com o objetivo de realizar uma reforma agrária baseada no direito burguês, portanto, uma reforma agrária capitalista, Arbenz foi tido 
como revolucionário e comunista pelos norte-americanos. Porém, a questão que estava por detrás da difamação de que Arbens era supostamente comunista era a de que a reforma agrária desafiava os interesses da United Fruit, companhia americana que explorava a produção de banana na Guatemala. Tanto, que no Caribe, um dos ditos mais populares era: Deus fez a banana; $o$ diabo fez a United Fruit. $\mathrm{O}$ fato é que os EUA financiaram e treinaram, fora do território da Guatemala, Castilho Armas, mercenário e traidor da pátria guatematelca e que derrubou o governo de Arbenz (COUTINHO E SILVEIRA, 1957).

O paradigma do capitalismo norte-americano se difundiu, mundialmente, pelo estímulo ao crescimento econômico através das políticas fiscais monetárias; pelo compromisso com a unidade global do mercado, baseado na produção de mais mercadorias por preços mais baixos e mais divisão do trabalho; pela adoção do dólar, como moeda de troca, pela maior parte dos países que compunham o sistema internacional; pelo emprego de ações neutralizadoras em relação ao bloco dos países socialistas. O objetivo daquelas ações era deter qualquer política econômica ideológica associada com a União das Repúblicas Socialistas Soviéticas (URSS); e, por fim, pelo esforço em manter as fronteiras políticas, fato este tensionado por meio da doutrina Truman (GEORGE, 1961; AGNEW E CORBRIDGE, 1995).

A defesa por Woodrow Wilson, então presidente dos EUA entre 1912 e 1921, do princípio da autodeterminação das nações transformou-se numa contraposição ao imperialismo territorial exercido pelas potências europeias. Assim, a bandeira da autodeterminação dos povos foi liderada pelos EUA. O objetivo era enfraquecer a influência das antigas potências europeias no plano das relações internacionais. Conjugado ao princípio da autodeterminação dos povos, os EUA defenderam também o estímulo ao desenvolvimento do Estado de bem-estar social com o objetivo de alavancar o consumo em massa (MORAES E COSTA, 1984; LIPIETZ, 1988; AGNEW E CORBRIDGE, 1995; WALLERSTEIN, 2002). É preciso destacar, porém, que quando os interesses das Corporações Americanas eram desafiados e ou ameaçados pelas políticas nacionais dos Estados onde elas estavam instaladas, os governos norte-americanos não deixaram de intervir, fosse de forma direta ou indiretamente como se demonstrou anteriormente (LIPIETZ, 1988).

A ascensão dos EUA como potência hegemônica do sistema internacional, como se demonstrou, se deu através da articulação das instituições supra-estatais e das corporações transnacionais que se transformaram nos tentáculos dos EUA. E o corpus teórico da geopolítica formulado, sobretudo, pelos geógrafos alemães exerceu enorme influência no 
raciocínio dos geoestrategistas norte-americanos precisamente Alfred Mahan e seu expoente Nicholas Spykman (LACOSTE, 1998; COSTA, 2008).

Ainda, nos EUA a Geografia ficou praticamente restrita às Universidades. Logo, os geógrafos norte-americanos ou iam trabalhar para os governos ou iam para as sociedades geográficas. As Geografias francesas e alemãs formavam os professores de geografia para atuarem no ensino secundário. Assim, por um lapso de tempo (1945-1970), o raciocínio Geopolítico ficou encoberto, ao menos nas teorizações francesas e alemãs, diferentemente do que ocorreu na Geografia norte-americana, em que Geopolítica continuou a ser suporte tanto para ação do Estado quanto para ação das Corporações.

Com o fim da ordem geopolítica da Guerra Fria (1990) que foi marcada, sobretudo, pela crise econômica que atingira o mundo como um todo e pelo desmantelamento da URSS, a ordem geopolítica do Liberalismo Transnacional emergiu assentada nos pilares do livre comércio, no ideário do Estado mínimo (nenhuma intervenção estatal na economia), na crença de que os mercados são confiáveis e transparentes e que as Corporações gerem melhor os recursos (AGNEW E CORBRIDGE, 1995). Sob o Liberalismo Transnacional, a hegemonia norte-americana ainda se faz presente em todo o mundo, mas o poder dos Estados nacionais foi duramente golpeado como se altercará na próxima seção.

\section{Liberalismo Transnacional: o mundo sob a hegemonia das Corporações}

Após 1945, a orquestração dos três agentes supra-estatais (FMI, BIRD e GATT) articulada às grandes Corporações Cosmopolitas e ou Transnacionais, sobretudo, norte-americanas não apenas impulsionaram a mundialização econômica ou a globalização como se constituíram nos tentáculos dos EUA sobre os Estados nacionais periféricos e semi-periféricos do sistema internacional. Os elementos que constituíram a ordem geopolítica do Liberalismo Transnacional - liberalização do comércio entre as nações e a liberalização dos mercados de capitais - foram se difundindo e desafiando as soberanias nacionais em todas as partes do globo.

A década de 1970 foi marcada por uma crise econômica mundial (LIPIETZ, 1988; SEABRA, 1996; COSTA, 2008). De acordo com Arrighi (1996), a crise econômica mundial entre as décadas de 1970 e 1980 não constituía novidade, tendo em vista que no decorrer do desenvolvimento do capitalismo histórico, outras crises similares já haviam ocorrido e coincidiam com as fases de transição de um ciclo de acumulação capitalista para outro. E 
como explicitou Lipietz (1988), as crises do capitalismo revelam a inadequação dos elementos de regulação num regime de acumulação.

Não obstante, a emergência de um pensamento econômico respaldado nos princípios neoliberais irá aduzir que a crise dos anos 1970 estava relacionada com o excesso de intervencionismo estatal na economia e que a solução seria tornar o mercado mais livre e menos regulado (PEET, 2007). Assim, as instituições supra-estatais que antes estavam respaldadas nos pressupostos keynesianos foram convertidas às doutrinas neoliberais:

\footnotetext{
a mudança mais drástica nestas instituições [FMI, BIRD, GATT] registrou-se nos anos 80, época em que Ronald Reagan [Presidente dos EUA] e Margaret Thatcher [Primeira Ministra Britânica] pregavam a ideologia do mercado livre nos Estados Unidos e na Grã-Bretanha. O FMI e o Banco Mundial tornaramse as novas instituições missionárias, através das quais estas idéias eram impostas aos países pobres (STIGLITZ, 2004, p. 49).
}

A ascensão do neoliberalismo possibilitou algo muito maior do que o reavivamento das instituições de Bretton Woods. Os pressupostos neoliberais tornaram tangíveis o liberalismo transnacional. Este que emergiu na década de 1970 teve em Milton Friedman e em Friedrich Von Hayek o suporte intelectual. A idéia básica do neoliberalismo é a de que os mercados são transparentes. Outra concepção do transnacionalismo liberal é "relacionar o desenvolvimento econômico com uma disposição para ganhar acesso ao mercado" (AGNEW E CORBRIDGE, 1995, p. 201).

Para os defensores do neoliberalismo, a tendência é a de que as elites locais irão se tornar cada vez mais uma entidade transnacional: "o principal ponto que queremos chegar ao considerar o suporte da elite para o liberalismo transnacional é que qualquer que seja a elite deve agora ela própria ser vista como uma entidade transnacional (ou do tipo que integra o interesse do grupo)" (AGNEW E CORBRIDGE, 1995, p. 201).

As concepções neoliberais de Hayek passaram a ser aplicadas no Reino Unido no decorrer dos anos de 1970. Para aquele teórico do neoliberalismo uma das regras básicas para sociedades capitalistas é a de que a função do Estado deve ser mínima. Concomitantemente com a revalorização do liberalismo, na década de 1970 as idéias da escola da dependência também ganharam destaque. Para esta escola os países ricos o são por conta da exploração que exercem sobre os países pobres. Assim, países pobres e ricos são interdependentes (LIPIETZ, 1988; HOUTART, 2010).

Desse modo, o surgimento do Liberalismo Transnacional no decurso dos anos de 1970, se constituiu num grande divisor de águas, porque 
significou: 1) o aprofundamento do liberalismo econômico; 2) a formação dos Blocos Econômicos (na Europa, na Ásia e na América Latina); 3) a emergência do movimento ecológico global; 4) a passagem de um regime de acumulação fordista-keynesiano para regime de acumulação flexível e 5) o domínio do poder financeiro transnacional sobre o Estado nacional (LIPIETZ, 1988; AGNEW E CORBRIDGE, 1995; ARRIGHI, 1996; BECK, 1999; SANTOS, 2004; BECKER, 2006; PEET, 2007; HOUTART, 2010).

Mesmo adotando progressivamente medidas mais liberalizantes, como a abertura das economias domésticas aos investimentos externos, nem todos os Estados nacionais lograram êxitos expressivos quanto ao crescimento e desenvolvimento econômicos. Pelo contrário, o que se viu na década de 1980 foram o maior endividamento e a maior dependência daqueles países em relação aos empréstimos concedidos pelo FMI e BIRD sob determinadas exigências. Atualmente, a crise da dívida e as medidas de austeridade econômica afetam a Zona do Euro, sobretudo os países menos dinâmicos economicamente (STIGLITZ, 2004).

Os baluartes do Liberalismo Transnacional - FMI, BIRD e o Tesouro dos Estados Unidos - continuaram a defender as teses do mercado livre como sendo a solução para os países mais pobres do sistema internacional conseguirem estabilizar suas economias domésticas. Assim, as décadas de 1980 e 1990 foram marcadas pela ampla adesão, sobretudo dos países da América Latina, à implementação de medidas de austeridade orçamentária, de privatizações e de liberação dos mercados. Todas essas políticas econômicas derivadas das instituições promotoras do neoliberalismo ficaram conhecidas como o Consenso de Washington (AGNEW E CORBRIDGE, 1995; STIGLITZ, 2004; HOUTART, 2010).

Os países que seguiram os princípios defendidos pelo Consenso de Washington tiveram suas economias domésticas arruinadas. Em geral, as privatizações das empresas públicas nacionais, constituídas a duras penas foram realizadas rapidamente, o que acabou concorrendo para o desemprego e formação de monopólios. A redução das barreiras alfandegárias, por parte dos países em desenvolvimento, ampliou as exportações de maquinarias e serviços dos países ricos e industrializados. Não obstante, os países industrializados continuaram a manter suas políticas protecionistas (subsídios aos agricultores), impedindo que os países periféricos e semi-periféricos exportassem os seus produtos para os mercados dos países centrais (STIGLITZ, 2004; HOUTART, 2010).

Ademais, a liberação de mercados de capitais, que até 1970 tinha ficado de fora das políticas liberais, provocou grandes fluxos de capitais especulativos que passaram a entrar e a sair pelas fronteiras com uma 
velocidade que inviabilizava (ainda tende a inviabilizar) o controle deles por parte dos Estados. Assim, no que diz respeito à Geopolítica, a desnacionalização e desterritorialização do dinheiro colocou em xeque a soberania dos Estados: "não está claro como os estados podem efetivamente controlar o dinheiro nacional e internacional" (AGNEW E CORBRIDGE, 1995, p. 176). Portanto, a circulação de dinheiro hoje é um desafio à soberania dos Estados territoriais, pois que o dinheiro não respeita fronteiras. Os mercados de trocas financeiras funcionam 24 horas seja pelo computador e ou por telefone.

Se o dinheiro deixou de ter pátria, então seria o fim da Geografia? Não necessariamente, porque "as diferenças em níveis de investimentos entre pessoas ricas e pobres e lugares continuam sobre uma base extensa do globo" (AGNEW E CORBRIDGE, 1995, p. 177). Assim, o fato de haver distinções quanto aos níveis de investimentos entre os lugares mostra que os impactos da abertura dos mercados de capitais atingem os Estados de maneira diferenciada, afetando com mais intensidade as economias periféricas e semiperiféricas:

\begin{abstract}
(...) Isto é válido para todos os fluxos, mas se nos detivermos especificamente ao movimento do capital financeiro, por exemplo, veremos que nesse caso pode-se falar numa circulação a-espacial. (...) Se o valor do espaço é desigualmente distribuído, também o valor no espaço manifesta-se em intensidades variáveis: alguns lugares "sintetizam" mais todo o mundo, do que outros. Aí estão os centros hegemônicos do capitalismo e a hierarquização rígida das relações entre nações, impossibilitando o desenvolvimento dos capitalismos "autônomos", como a melhor evidência dessa contradição (MORAES E COSTA, 1984, p. 168).
\end{abstract}

Os efeitos desses fluxos de capitais sem controle, em muitos casos, tendem a ser nefastos:

\begin{abstract}
Por muito nociva, prematura e mal gerida que a liberalização do comércio tenha sido para os países em desenvolvimento, em muitos aspectos a dos mercados de capitais foi ainda pior. A liberalização dos mercados de capitais implica o desmantelamento das regulamentações destinadas a controlar o fluxo de capitais especulativos que entram e saem do país empréstimos de curto prazo e contratos que em geral não passam de apostas sobre a evolução da taxa de câmbio. Estes capitais especulativos não podem ser utilizados para construir fábricas nem para criar postos de trabalho (STIGLITZ, 2004, p. 109).
\end{abstract}

$\mathrm{O}$ que se viu nos países que seguiram à risca os pressupostos do Consenso de Washington, como foi o caso da Argentina, foi o crescimento do 
desemprego, da pobreza e da violência urbana. Estes acontecimentos resultaram no aumento da instabilidade social e o poder de ação do Estado para contornar esses dilemas havia ficado limitado.

Em linhas gerais, a globalização acompanhada dos princípios de liberalização econômica - mercado de capitais, desregulamentação das finanças, redução das taxas alfandegárias, investimentos estrangeiros significou, por um lado, mais poder e oportunidade para as Corporações Transnacionais, bancos e outros atores hegemônicos atuarem livremente no mundo. Essas elites têm um grande interesse na não intervenção do Estado na economia porque elas tendem a ganhar mais (AGNEW E CORBRIDGE, 1995; BECK, 1999; BECKER, 2006; PEET, 2007).

E, por outro lado, o Liberalismo Transnacional engendrou maiores desafios para a intervenção estatal nas economias nacionais. Não há dúvidas de que a globalização econômica concorreu para o compartilhamento do poder do Estado territorial com as Instituições Supranacionais e com as Corporações Transnacionais. Houve o aumento do número de instituições não estatais e internacionais que passaram a organizar, promover e participar de conferências, acordos regulatórios juntamente com os Estados. Em outras palavras: a fazerem suas próprias Geopolíticas (NYE E KEOHANE, 1971; AGNEW E CORBRIDGE, 1995; BECK, 1999).

Não obstante, a internacionalização das atividades estatais (estabelecimento de tratados, acordos entre outras ações) tende a ser desigual. Países mais fracos e endividados economicamente têm sua soberania limitada por conta da ingerência das instituições supra-estatais como o FMI, Banco Mundial (BECK, 1999). Como se sabe, o FMI é uma instituição internacional pública e que recebe contribuições dos países signatários do Acordo de Bretton Woods, "mas os grandes países desenvolvidos é que ditam as regras, e só um deles, os Estados Unidos, é que têm direito de veto efetivo" (STIGLITZ, 2004, p. 49).

Outro dado importante na ordem geopolítica do Liberalismo Transnacional é a de que uma Corporação Transnacional pode ser economicamente muito maior do que muitos países. Os investimentos das corporações, para além dos seus territórios de origem, provocam desarranjos em virtude dos seus contínuos deslocamentos à procura de melhores condições e de espaços vitais. Assim, a Geopolítica enquanto saber estratégico que guiava a ação dos Estados nacionais fora incorporado pelas Corporações:

(...) à geografia dos dirigentes do aparelho de Estado, estruturando o seu espaço em províncias, departamentos, distritos, à geografia dos exploradores (oficiais, frequentemente) que prepararam a conquista colonial e a valorização se anexou a 
geografia dos estados-maiores das grandes firmas e dos grandes bancos que decidem sobre a localização de seus investimentos em plano regional, nacional e internacional (LACOSTE, 1998, p. 26).

Assim, essa crescente internacionalização e o crescente poder das Corporações, como já se afirmou, desafiam a soberania das economias territoriais. Porém, o Liberalismo Transnacional não aboliu o protecionismo econômico. Pelo contrário, medidas restritivas têm sido usadas contra os países pobres para favorecer as nações mais ricas e prósperas. (AGNEW E CORBRIDGE, 1995; SANTOS, 2004; STIGLITZ, 2004).

$\mathrm{Na}$ atual conjuntura de desregulação e crescente desnacionalização das economias territoriais, os EUA passaram a reconhecer que o mercado mundial - o novo Leviatã - tem de ser controlado em conjunto e em cooperação com os outros países. Assim, o Grupo dos Sete países mais ricos (G7) e do G20 têm conquistado relevância no contexto do Liberalismo Transnacional para o enfrentamento do ônus que a economia mundial desterritorializada tende a acarretar, sobretudo, para os países periféricos e semi-periféricos.

A globalização econômica, mesmo em menores proporções, também impactou o bem-estar dos norte-americanos. As práticas neoliberais resultaram no aumento do número de pobres e na redução da classe média que teve os salários diminuídos. Não obstante, os ricos ficaram mais ricos. O Liberalismo Transnacional também atingiu as várias regiões dos EUA que tiveram decréscimo na qualidade de vida e ficaram alijadas dos investimentos, ocasionando fortes disparidades regionais. A questão é que os EUA investiram em outras regiões do mundo, o que foi bom para quem recebeu, mas fragilizou a sua própria economia doméstica (AGNEW E CORBRIDGE, 1995; COSTA, 2008).

Por fim, a crise da dívida que atingiu os países periféricos e semiperiféricos nas décadas de 1980 e 1990 acabou por acelerar o advento da 'soberania compartilhada' entre os países e as instituições supranacionais com vistas a controlar o Leviatã do mercado (e das finanças). Assim, a ordem geopolítica do Liberalismo Transnacional tem se caracterizado pela crescente desterritorialização dos poderes econômicos e políticos; pela fluidez das atividades que dinamizam o espaço; pela globalização da produção; pela soberania compartilhada e pelo poder das Corporações Transnacionais que se utilizam dos saberes geográficos estratégicos com o intuito de maximizarem seus lucros globais (AGNEW E CORBRIDGE, 1995).

Cabe destacar que sob a ordem geopolítica do Liberalismo Transnacional os EUA ainda desempenham papel de liderança no sistema 
internacional, pois que "o universalismo da cultura de um país e suas habilidades para estabelecer um tipo de regras favoráveis e instituições que governam áreas de atividade internacional são fontes críticas de poder" (AGNEW E CORBRIDGE, 1995, p. 117).

Num período em que a economia política internacional tem se estruturado na informação e na interdependência entre os países,

\begin{abstract}
o poder está se tornando menos transferível, menos tangível, e menos coercivo. No entanto, a transformação do poder está incompleta. O século XXI certamente verá um maior aumento da função do poder informacional e institucional, mas a força militar permanecerá como um fator importante. Economia de escala, ambos em mercado e recursos naturais, também permanecerão importantes (NYE, 1990, p. 183).
\end{abstract}

Como explicitou Nye (1990), a liderança norte-americana no mundo tende a ser um misto entre consenso e coerção. A difusão da cultura norteamericana pelo globo mostra que o declínio econômico dos EUA tem que ser visto com cautela. Supostos aspirantes ao poder mundial tais como China, Japão e Alemanha embora tenham se tornado países com grande crescimento econômico, ainda carecem de poder e capacidade de influir em âmbito mundial (AGNEW E CORBRIDGE, 1995).

Mesmo após a Guerra Fria, os EUA, portanto, continuam a exercer influência nos rumos do mundo, uma vez que a queda da URSS deixou "os EUA como o único líder do poder com uma mensagem global: consumo de massa, liberdade individual, propriedade privada, democracia eleitoral e de mercado" (AGNEW E CORBRIDGE, 1995, p. 134).

Em um sistema mundial que tem se caracterizado cada vez mais por uma "economia política global na qual nenhuma economia nacional particular tem um domínio completo e na qual muitos atores, incluindo as corporações multinacionais e bancos transnacionais, são globais em organização e visão de mundo" conforme examinaram Agnew e Corbridge (1995, p. 9), quais os dilemas enfrentados pelo Brasil num mundo em que as fronteiras estatais têm sido cada vez mais permeáveis para os fluxos derivados das redes de poder não apreendidas pelas especificidades das representações territoriais do espaço?

\title{
Cerrado brasileiro metamorfoseado em Soja e Cana: o poder corporativo
}

Como se demonstrou até aqui, as Corporações Transnacionais neste período de globalização, dividem, usam e abusam dos territórios com vistas a maximizarem os seus lucros e suas estratégias têm nos conhecimentos sobre os 
lugares o suporte imprescindível para compartimentarem a produção em âmbito global. O Brasil, por ser um país de grandes dimensões territoriais, exerce grande poder de atração sobre as corporações que atuam nos circuitos espaciais produtivos da soja e da cana-de-açúcar. Convém ressaltar que o circuito espacial produtivo diz respeito a um arranjo sócio-espacial que interconecta os vários momentos da produção de um bem e ou serviço.

Conforme as proposições de Marx (2008) acerca da acumulação do capital, entre a produção e o consumo há as etapas da circulação e da troca (mercado). Isto significa que para o bem ou serviço produzido numa dada unidade produtiva atinja a outra ponta - o consumo - é preciso viabilizar a circulação por meio dos sistemas de transporte e de armazenamento. Ainda sobre o conceito de circuito espacial produtivo, Castillo e Frederico (2010, p. 463) consideram que "a noção de circuito espacial produtivo enfatiza, a um só tempo, a centralidade da circulação (circuito) no encadeamento das diversas etapas da produção; a condição do espaço (espacial) como variável ativa na reprodução social; e o enfoque centrado no ramo, ou seja, na atividade produtiva dominante (produtivo)".

Feita essa consideração sobre o conceito de circuito espacial produtivo, o fato é que em 2008 observou-se grande número de fusões e aquisições no segmento produtivo do açúcar e do álcool que até então se caracterizava pela relativa desconcentração e ou pulverização, pois o controle das usinas estava vinculado a famílias tradicionais ligadas ao setor. Atualmente, o que tem ocorrido progressivamente é a concentração do setor por apenas alguns grupos nacionais que têm se associado às Corporações Transnacionais. Não obstante, as fusões e aquisições são um processo que vem ocorrendo desde 2000 (HOUTART, 2010).

Na tabela 1 foram elencados as Corporações Transnacionais que têm atuado, no Brasil, no setor de açúcar e álcool, sendo que algumas Corporações controlam também a produção de soja, como é o caso da Cargill (maior corporação global do setor do agronegócio), da Bunge e da ADM. Chegou-se a esses dados através do acompanhamento de mídia especializada, sites de empresas e artigos científicos: 


\section{Tabela 1}

Corporações envolvidas no setor sucroalcooleiro brasileiro e país de origem

\begin{tabular}{|c|c|}
\hline $\begin{array}{c}\text { Corporações transnacionais envolvidas } \\
\text { com a produção de açúcar e álcool (2000- } \\
2012)\end{array}$ & $\begin{array}{l}\text { Países de origem } \\
\text { (do capital) }\end{array}$ \\
\hline Adecoagro & EUA (George Soros investidor) \\
\hline ADM (Archier Daniels Midland) & EUA \\
\hline AGREG & Brasil + Fundos estrangeiros \\
\hline Amyris & EUA \\
\hline BP (British Petroleum) & UK \\
\hline BRENCO & Brasil + Fundos estrangeiros \\
\hline BUNGE & Holanda \\
\hline Cargill & EUA \\
\hline Coinbra/Dreyfus = LDC Louis Dreyfus Bionergia & França + Brasil \\
\hline Eridania Beghin Say (EBS) & França \\
\hline Evergrenn & Rússia \\
\hline Glencore Intl AG & Suíça \\
\hline Global Energy & Espanha \\
\hline Globex & EUA \\
\hline Grupo Stanely Morgan & EUA \\
\hline Mitsubshi Corporation & Japão \\
\hline Mitsui & Japão \\
\hline Tereos & França \\
\hline Toyota Tshusho & Japão \\
\hline Trading Noble Group & Hong Kong \\
\hline Trading Sucden & França \\
\hline Truenergy & EUA \\
\hline
\end{tabular}

Fonte: Valor Econômico (2008-2012); sites das empresas pesquisadas e Maria Domingues Benetti, 2008, p. 7. Organização: Autora.

Atualmente, as cinco maiores Corporações que atuam no circuito espacial produtivo do açúcar e do álcool já respondem por $43 \%$ da moagem de cana-de-açúcar no Brasil. Convém destacar que no setor sojicultor o nível concentração é de $64 \%$ e no suco de laranja é de $92 \%$. Entre 2000 e 2008, as Corporações com sede nos EUA e na França, lideraram o processo de aquisições das usinas de açúcar e álcool brasileiras como poder verificado na tabela 2: 
Tabela 2

Aquisição de Usinas de Açúcar e Álcool por Corporações Estrangeiras (2000-2008)

\begin{tabular}{|c|c|c|}
\hline $\begin{array}{l}\text { Grupo estrangeiro } \\
\text { comprador }\end{array}$ & Usinas cobiçadas & $\begin{array}{l}\text { Local (Estados da } \\
\text { Federação) }\end{array}$ \\
\hline ADECOAGRO (EUA) & Monte Alegre & MG \\
\hline Bunge e Born (Holanda) & Santa Juliana & MG \\
\hline Cargill (EUA) & CEVASA & SP \\
\hline $\begin{array}{l}\text { Coinbra/Dreyfus/LCD } \\
\text { (França) }\end{array}$ & $\begin{array}{l}\text { Cresciumal } \\
\text { Luciânia } \\
\text { Usinas do grupo Tavares de } \\
\text { Melo } \\
\text { São Carlos }\end{array}$ & $\begin{array}{l}\mathrm{SP} \\
\mathrm{SP} \\
\mathrm{PB}, \mathrm{RN} \text { e MS } \\
\mathrm{SP}\end{array}$ \\
\hline $\begin{array}{l}\text { Eridania Beghin Say (EBS) } \\
\text { (França) }\end{array}$ & Guarani & SP \\
\hline $\begin{array}{l}\text { Franco } \\
\text { (FDA) }\end{array}$ & $\begin{array}{l}\text { Ipaussu S/A A\&A } \\
\text { Univalem } \\
\text { Santo Antônio }\end{array}$ & $\begin{array}{l}\mathrm{SP} \\
\mathrm{SP} \\
\mathrm{SP}\end{array}$ \\
\hline Glencore Intl AG (Suiça) & Portobello & SC \\
\hline Infinity Bio-Energy (EUA) & $\begin{array}{l}\text { UNISAVI } \\
\text { Alcana } \\
\text { CRIDASA } \\
\text { DISA } \\
\text { CELSA } \\
\text { Infisa }\end{array}$ & $\begin{array}{l}\text { MS } \\
\text { ES } \\
\text { ES } \\
\text { ES } \\
\text { ES } \\
\text { ES }\end{array}$ \\
\hline $\begin{array}{l}\text { KIDD \& Company (Fundo } \\
\text { de Investimentos) (EUA) }\end{array}$ & Coopernavi & MS \\
\hline Noble Group (Hong Kong) & Petribui & SP \\
\hline Tereos (França) & Paraguaçu-Parálcool & SP \\
\hline
\end{tabular}

Fonte: Valor Econômico (2008-2012); sites das empresas pesquisadas e Maria Domingues Benetti, 2008, p. 7. Organização: Autora

Os resultados da atuação das Corporações Transnacionais nos circuitos espaciais produtivos da soja e da cana se refletem na metamorfose de extensas 
áreas do Cerrado em produção de soja e de cana como pode ser verificados nas figuras 1 e 2:

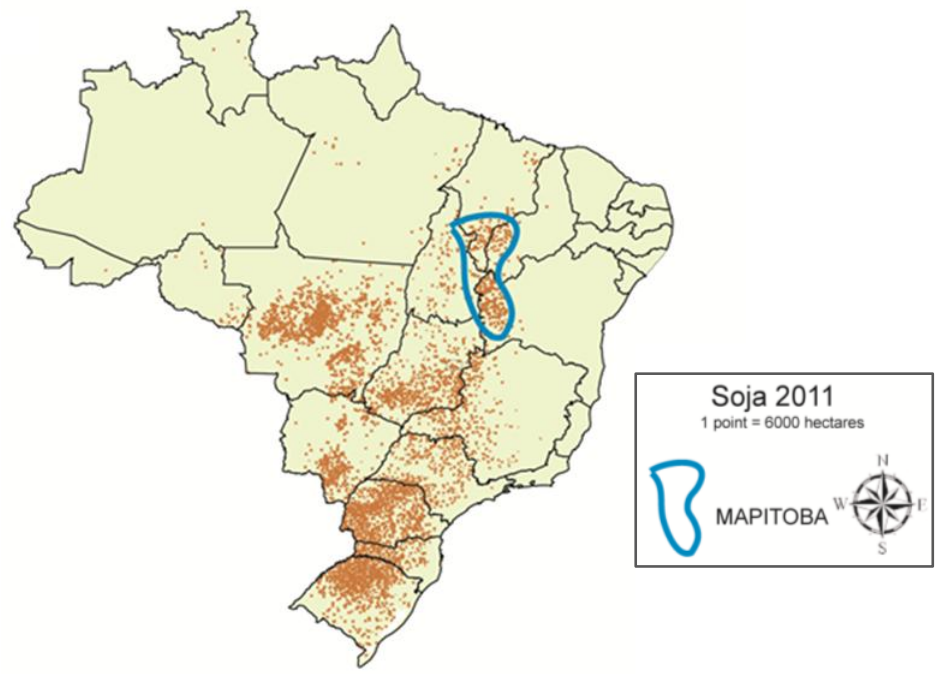

Figura 1. Brasil: área plantada com soja em 2011 (em hectares)

Fonte: Instituto Brasileiro de Geografia e Estatística (IBGE), 2012

Elaboração: Autora, com philcarto.

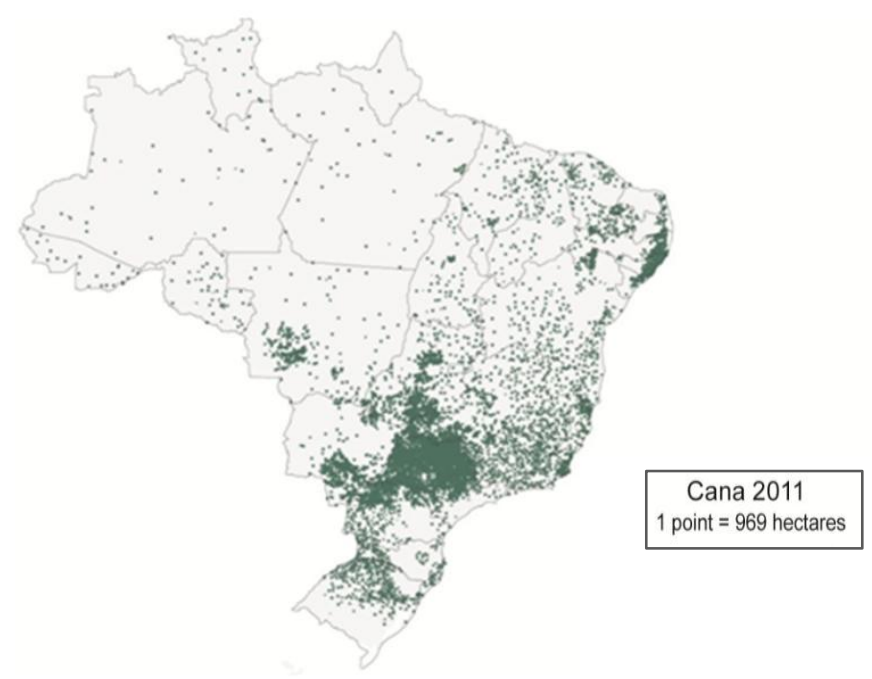

Figura 2. Brasil: área plantada com cana-de-açúcar em 2011 (em hectares) Fonte: Instituto Brasileiro de Geografia e Estatística (IBGE), 2012 Elaboração: Autora, com philcarto. 
Convém ressaltar que em virtude da crescente demanda global por soja, a região de encontro entre os estados do Maranhão, Piauí, Tocantins e Bahia (última fronteira agrícola do Cerrado) tem sido ocupada por grandes projetos agropecuários controlados pelas Corporações Transnacionais. E essa região é atualmente denominada de MAPITOBA (ver figura 1). No Brasil, o cultivo da soja ocupa uma área de 24 milhões de hectares ou 9\% de toda a área agricultável do país, segundo os dados do Ministério de Agricultura, Pecuária e Abastecimento (MAPA). A área ocupada com a cana-de-açúcar responde por 9 milhões de hectares. No entanto, estima-se que nos próximos anos a área plantada com cana-de-açúcar possa atingir os 13 milhões de hectares à medida que as áreas de pastagem forem sendo incorporadas por aquele cultivo. $\mathrm{O}$ aumento da produção de ambos os cultivos também se vincula ao mercado global dos biocombustíveis (FREITAS, 2013).

A metamorfose do Cerrado em soja e em cana também é resultado das estratégias Geopolíticas que nortearam o Estado brasileiro entre os períodos de 1964-1988. O Capítulo III do Primeiro Plano Nacional de Desenvolvimento (I PND) trazia as estratégias a serem adotadas pelo Estado para viabilizar o crescimento e o desenvolvimento econômico nacional. Assim, as principais estratégias eram incentivar a expansão da fronteira econômica tendo em vista a dimensão do território nacional, fortalecer a indústria e a agricultura por meio da modernização, investir fortemente nos setores de energia, transporte e comunicação com vistas a ampliar a integração territorial, ou melhor, articular a heartland à hinterland (FREITAS, 2013).

Atualmente, como grande parte das terras agricultáveis produz cultivos para a exportação, a produção de alimentos tende a ficar comprometida. O valor da produção da soja e da cana-de-açúcar em 2011 foi de $\mathrm{R} \$ 50,3$ e R \$ 39, 2 bilhões respectivamente, segundos os dados do IBGE. Já o valor da produção do feijão e do arroz, alimentos que compõem a cesta básica, foi de $\mathrm{R} \$ 5,1$ e $\mathrm{R} \$ 5,8$ bilhões respectivamente. Convém destacar que em 2012 o Brasil importou feijão preto da China.

O ordenamento do território que pode ser compreendido como sendo "a regulação das tendências de distribuição das atividades produtivas e equipamentos no território nacional ou supranacional decorrente das ações de múltiplos atores, segundo uma visão estratégica e mediante articulação institucional e negociação, de modo a alcançar os objetivos desejados" (MINISTÉRIO DA INTEGRAÇÃO NACIONAL, 2006, p. 10), deixou de ser uma prerrogativa dos Estados nacionais, uma vez que as Corporações Transnacionais (des) organizam os territórios de acordo com as estratégias de mercado. E o Estado nacional quando não intervém nas Geopolíticas das Corporações, ampara-as com empréstimos e financiamentos ou se omite 
quando uma ação corporativa concorre para o prejuízo de toda a sociedade nacional (SANTOS, 2004).

\section{Considerações finais}

Como se buscou demonstrar, o conhecimento sobre os lugares, as regiões, os territórios é de suma importância para que agentes políticos e econômicos tracem e planejam suas estratégias ou Geopolíticas. Não obstante, com a ascensão dos EUA na condição de superpotência do sistema internacional pós-1945, as Corporações Transnacionais e as instituições supraestatais passaram a atuar, em cada porção do espaço geográfico, como verdadeiros tentáculos do poder norte-americano. E a Geopolítica, conhecimento estratégico que compunha o métier da arte de governar, passou a ser de interesse também às grandes firmas multinacionais. Assim, nesta ordem geopolítica do Liberalismo Transnacional a disputa por territórios e ou espaços vitais, recursos naturais e poder tem sido conduzida também pelas Corporações Transnacionais que tendem a compartimentar a produção em âmbito global com vistas a explorar, diferencialmente, o que cada porção do espaço geográfico pode lhe oferecer em termos de vantagens comparativas.

Assim, a concepção de Geopolítica (que hoje deverá ser crítica) deve levar em consideração que os múltiplos atores que atuam tanto globalmente quanto localmente dividem o espaço em suas esferas de influências. E o Estado nacional, embora seja o ator responsável pela organização territorial do globo, não é o único ator que conduz as disputas e ou conflitos na arena internacional. As Corporações Transnacionais também competem entre elas e subordinam os Estados para conseguirem atingir os seus propósitos.

\section{Referências}

AGNEW, John; CORBRIDGE, Stuart. Mastering Space. Hegemony, territory and international political economy. London/New York: Routledge, 1995, 260p.

ARRIGHI, Giovanni. O longo século XX. Trad. Vera Ribeiro. Rio de Janeiro: Contraponto; São Paulo: Editora Unesp, 1996. 408p.

BECK, Ulrich. O que é globalização? Equívocos da globalismo resposta à globalização. Trad. André Carone. São Paulo: Paz e Terra, 1999, 282p.

BECKER, Bertha K. A geopolítica na virada do milênio: logística e desenvolvimento sustentável. In: CASTRO, I. E. et al. Geografia: conceitos e temas. 8 ed. Rio de Janeiro: Bertrand Brasil, 2006, p. 271-307. 
CAPEL, Horácio. Filosofía y ciencia em La Geografía contemporânea: una introducción a la Geografía. Barcelona: Editorial Barcanova, 1983, 509p.

CASTILLO, Ricardo; FREDERICO, Samuel. Espaço geográfico, produção e movimento: uma reflexão sobre o conceito de circuito espacial produtivo. Sociedade \& Natureza, Uberlândia, n. 22, p. 461-474, dez. 2010.

CASTRO, Iná Elias de. Geografia e Política: território, escalas de ação e instituições. Rio de Janeiro: Bertrand Brasil, 2005. 304p.

COSTA, Wanderley M. O Estado e as políticas territoriais no Brasil. São Paulo: Contexto, 1988.

COSTA, Wanderley M. Geografia Política e Geopolítica. 2. ed. São Paulo: Edusp, 2008, 349p.

COUTINHO, Lourival; SILVEIRA, Joel. Petróleo no Brasil: traição e vitória. Rio de Janeiro: Livraria Editora Coelho Branco, 1957.

FREITAS, Elisa Pinheiro de. Território, Poder e Biocombustíveis: as ações do Estado brasileiro no processo de regulação territorial para a produção de recursos energéticos alternativos. São Paulo: FFLCH-USP, 2013. 501p. (Tese de Doutorado em Geografia Humana - FFLCH-USP).

GEORGE, Pierre. Geografia Econômica. Trad. Ruth Magnanini. Rio de Janeiro: Editora Fundo de Cultura, 1961, 333p.

GEORGE, Pierre. Vida e obra de Max Sorre. Boletim Geográfico, n. 201, Novdez/1967, p. 15-22.

GEORGE, Pierre. Problemas, doutrina e método. In: GEORGE, Pierre et. al. A Geografia Ativa. 5. ed.Tradução: Gil Toledo, Manuel Seabra e Nelson de La Côrte. São Paulo/Rio de Janeiro : Difel editorial, 1980, 9-40p.

GOTTMANN, Jean. Geography and internacional relations. Word Politics, v. 3, n. 2, 1951, p. 153-173.

GRAMSCI, Antônio. Maquiavel, a política e o Estado moderno. Rio de Janeiro: Civilização Brasileira, 1975.

HARTSHORNE, Richard. The Nature of Geography. A critical survey of current thought in the light of the past. New York: Association of American Geographers, 1939. 482p.

HOUTART, François. A agroenergia. Solução para o clima ou saída da crise para o capital? Petrópolis: Editora Vozes, 2010, 324p. 
LACOSTE, Yves. A Geografia - Isso serve, em primeiro lugar, para fazer a guerra. São Paulo: Papirus, 1998.

LIPIETZ, Alain. Mirages e milagres: problemas da industrialização no terceiro mundo. Trad. Catherine Marie Mathieu. São Paulo: Ed. Nobel, 1988, 231p.

MAQUIAVEL, N. Discursos sobre a primeira década de Tito Lívio. São Paulo: Martins Fontes, 2007. 471p. (Obras de Maquiavel).

MARX, Karl. O capital. Crítica da economia política: livro I. Trad. Reginaldo Sant’Ana. 25 ed. Rio de Janeiro: Civilização Brasileira, 2008. 966p.

MINISTÉRIO DA INTEGRAÇÃO NACIONAL. Política Nacional de Ordenamento Territorial. Brasília, DF: Associação Brasileira de Pesquisa Tecnológica, 2006, 251p.

MORAES, Antonio Carlos Robert; COSTA, Wanderley Messias da. Geografia Crítica. A valorização do Espaço. São Paulo: Hucitec, 1984, 196p.

MORAES, Antonio Carlos Robert; COSTA, Wanderley Messias da. A Geografia e o processo de valorização do espaço. In: Novos rumos da geografia brasileira (Org.) SANTOS, Milton. 4 ed. São Paulo: Hucitec, 1996, 111-130p.

NYE, Joseph S.; KEOHANE, Robert O. Transnational relations and World Politics: an introduction. International Organization, New York, v. 25, n. 3, p. 329-349, jun./set. 1971.

NYE, Joseph S. Jr., The changing nature of world power political. Science Quarterly, v.105, Issue 2, p.177-192, Summer, 1990.

PEET, Richard. Geography of power: the making of global economy policy. London/New York: Zed Books, 2007, 225p.

RATZEL, Friedrich. Antropogeografia. Trad. MORAES, Antônio Carlos Robert. São Paulo: Editora Ática, 1990, 199p. (Coleção Grandes Cientistas Clássicos).

SANTOS, Milton. Por uma outra globalização: do pensamento único à consciência universal. Rio de Janeiro: Record, 2004, 174p.

SEABRA, Manoel Fernando Gonçalves. Crise econômico-social no Brasil o limite do espaço. In: Novos rumos da geografia brasileira (Org.) SANTOS, Milton. 4 ed. São Paulo: Hucitec, 1996, 166-180p.

SOJA, Edward W. Geografias Pós-modernas. A reafirmação do espaço na teoria social crítica. Trad. Vera Ribeiro. Rio de Janeiro: Zahar, 1993, 324p. 
STIGLITZ, Joseph E. Globalização. A grande desilusão. Trad. Maria Filomena Duarte. 3 ed. Lisboa: Terramar, 2004, 321p.

WALLERSTEIN, Immanuel. Após o liberalismo. Em busca da reconstrução do mundo. Trad. Ricardo Anibal Rosenbush. Petrópolis, RJ: Vozes, 2002, 271p.

\section{Elisa Pinheiro de Freitas}

Doutora em Geografia Humana pela Universidade de São Paulo com estágio de doutoramento na Universidade de Lisboa.

Pesquisadora do Laboratório de Geografia Política e Planejamento Territorial e Ambiental (LABOPLAN), do Departamento de Geografia da Universidade de São Paulo.

Avenida Prof. Lineu Prestes, 338.

Cidade Universitária. CEP: 05508-080 - Caixa Postal:72042 - São Paulo.

Cep: 05508-080 - São Paulo, SP - Brasil.

E-mail: elisafreitas@usp.br

Recebido para publicação em maio de 2013 Aprovado para publicação em junho de 2013 